
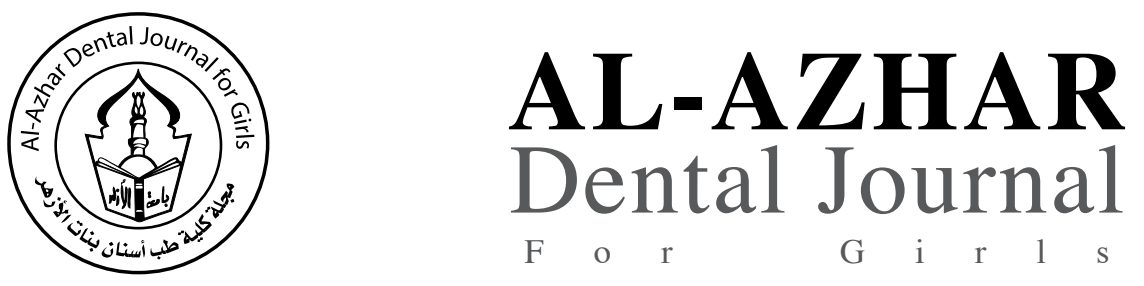

The Official Publication of The Faculty of Dental Medicine For Girls, Al-Azhar University Cairo, Egypt.

ADJ-for Grils, Vol. 3, No. 2, April (2016) — PP. 125:133

\title{
Effect of Food Simulating Liquids and Thermo-cycling on flexural strength and surface hardness of a Resin Nano-Ceramic CAD/CAM Material
}

\author{
Ahmed M. Sayed ${ }^{(1)}$, Maha A. Niazy ${ }^{(2)}$ and Inas T. Motawee ${ }^{(3)}$
}

Codex : 06/1604

dentaljournal.forgirls@yahoo.com

\begin{abstract}
Purpose: Evaluate the effect of food simulating liquids and thermocycling on miniflexural strength and surface micro-hardness of a resin nano-ceramic material (Lava Ultimate) compared to indirect laboratory composite resin material (Nexco Paste) and direct composite resin material (Filtek Z350 XT).
\end{abstract}

Material and Methods: A total number of 180 samples were fabricated. The samples were divided equally into 3 groups $(n=60)$. Group $1\left(M_{1}\right)$ samples were fabricated from the resin nano ceramic CAD/CAM blocks (Lava Ultimate), group $2\left(\mathrm{M}_{2}\right)$ samples were farbricated form indirect micro-hybrid resin composite (Nexco Paste), while group $3\left(\mathrm{M}_{3}\right)$ samples were fabricated from direct resin composite (Filtek Z350 XT). Thirty bars $(12 \mathrm{X} 2 \mathrm{X} 2 \mathrm{~mm})$ from each material were fabricated to evaluate the mini flexural strength. Thirty disks $(8 \mathrm{X} 2 \mathrm{~mm})$ were fabricated from each material to evaluate the surface micro-hardness. The samples of $M_{1}$ groups were fabricated by cutting from the $\mathrm{CAD} / \mathrm{CAM}$ block using low speed diamond disk while samples of $\mathrm{M}_{2}$ and $\mathrm{M}_{3}$ samples were fabricated using teflon mold. Each material samples were further subdivided into 6 subgroups; the first subgroup was not immersed into food simulating liquids nor thermocycled, 4 subgroups samples were immersed into food simulating liquids (water, ethanol, heptane and citric acid) and the last subgroup samples were thermocycled. Mini flexural strength test was done using universal testing machine and surface hardness was done using Vickers hardness tester.

Results: Lava Ultimate showed the significantly highest mini flexural strength and surface micro-hardness values before and after immersion into food simulating liquids and thermocycling compared to the two other tested materials.

Conclusion: According to the results of the present study, Lava Ultimate showed better mini flexural strength and surface micro-hardness compared to the two other tested materials.

1. Assistant Lecturer of Dental Biomaterials, Faculty of Dentistry, Modern University for Technology and Information, Egypt.

2. Professor and Head of Operative Dentistry Department, Faculty of Dentistry (Girls), Al-Azhar University, Egypt.

3. Assistant Professor and Acting Head of Dental Bioamterials Department, Faculty of Dentistry (Girls), Al-Azhar University, Egypt. 


\section{INTRODUCTION}

The resin composite restorative material offers a good solution for both the dentist and the patient who is seeking for a highly esthetic restoration with minimal removal of tooth structure ${ }^{(1)}$. Addition of nano-fillers to the resin matrix provides the improvement of the flexural strength, modulus of elasticity, diametral tensile strength, microhardness ${ }^{(2)}$, fracture toughness ${ }^{(3)}$ and wear resistance of dental resin composite ${ }^{(4)}$. The nano-filled resin composite showed lower surface roughness values more than the micro-hybrid and nano-hybrid resin composites $^{(5-7)}$.

The introduction of the CAD/CAM technology in the field of dentistry leads to many benefits such as; saving time, decrease administration of local anesthesia and avoiding using impression and temporary restorations ${ }^{(8)}$. A new CAD/CAM resin nano-ceramic restoration (Lava Ultimate) is available now at the dental market. This new material contains nanofillers imbedded into a highly cross linked resin matrix.

The food/oral simulating liquids have been recommended by the Bureau of Food, FDA. Some of them do exist in the mouth while, others can simulate its conditions (ingredients, $\mathrm{pH}$, viscosity). Their use enables us to see a fast wear of the materials in short time and furthermore to take in consideration processes like chemical affinity, elution or bonding. It goes without saying that physical/mechanical properties are influenced profoundly by the presence of the food simulating liquids ${ }^{(9)}$. Food simulating fluids can simulate the oral environment; distilled water simulates the wet oral environment provided by saliva and water, while heptane simulates butter, fatty meats and vegetable oils. The citric acid and ethanol simulate certain beverages including alcohol, fruits candies and syrups ${ }^{(10)}$.

In order to increase the survival rate of indirect composite restoration, the manufacturers introduced many products with more modifications in both matrix and fillers. One of these products is Lava
Ultimate which is produced by $3 \mathrm{M}$ ESPE. Lava Ultimate is a resin nano ceramic restoration and supplied into blocks to be milled via Cerec ${ }^{\circledR} \mathrm{CAD} /$ CAM milling machine ${ }^{(11)}$. Lava Ultimate contains clusters of silanated nano ceramic particles imbedded into a highly cross linked resin matrix ${ }^{(11)}$. This product combines the two basic aesthetic restorations; dental resin composite and ceramic materials aiming to get the best benefits of both materials.

The flexural strength of the Lava Ultimate was examined after restoring the samples for 24 hours in dry air without any storage protocol and found that the composite resin materials showed higher flexural strength combined with relativity low flexural modulus and stated that this combination translates to an increased ability to withstand loading by undergoing more elastic deformation before failure ${ }^{(12)}$. Therefore, this study aims at evaluating the effect of food simulating liquids and thermocycling on the mini flexural strength and surface micro-hardness of a resin nano-ceramic CAD/CAM material.

\section{MATERIAL AND METHODS}

Three types of dental resin composite restorative materials were used in this study. The indirect dental resin composite inlays were cemented by self adhesive resin cement. The materials used in this study are listed in (table 1).

\section{Sample grouping}

A total number of 180 samples were fabricated. The samples were divided equally into 3 groups $(n=60)$. Group $1\left(M_{1}\right)$ samples were fabricated from the resin nano ceramic CAD/CAM blocks (Lava Ultimate), group $2\left(\mathrm{M}_{2}\right)$ samples were farbricated form indirect micro-hybrid resin composite (Nexco Paste), while group $3\left(\mathrm{M}_{3}\right)$ samples were fabricated from direct resin composite (Filtek Z350 XT).

Samples of each group were further subdivided into six suprgoups. The samples of each subgroup were further subdiveded into 2 classes of 5 samples each; bars $(12 \times 2 \times 2 \mathrm{~mm})$ for measuring the mini 
Table 1. The materials, compositions and manufacturers of the materials employed in this study.

\begin{tabular}{|c|c|c|}
\hline Material & Composition (wt \%) & $\begin{array}{l}\text { Manufacturer } \\
\text { (Lot No.) }\end{array}$ \\
\hline $\begin{array}{l}\text { CAD-CAM resin nano } \\
\text { ceramic blocks } \\
\text { (Lava }{ }^{\mathbf{T M}} \text { Ultimate) }\end{array}$ & $\begin{array}{l}\text { - Resins: Highly cross linked polymeric matrix of UDMA and TEGDMA } \\
\text { - } \quad \text { Fillers: }(80 \% \mathrm{wt}) \\
\text { - } \\
\text { - } \\
\text { - } \\
\text { Non-agglomerated, non-aggregated } 20 \mathrm{~nm} \text { silica fillers } \\
\text { Aggregated zirconia/silica cluster fillers }\end{array}$ & $\begin{array}{l}\text { 3M ESPE, USA } \\
\text { (N842943) } \\
\text { Shade: A3.5 }\end{array}$ \\
\hline $\begin{array}{l}\text { Indirect Micro-hybrid } \\
\text { resin composite } \\
\text { (Nexco }{ }^{\circledR} \text { Paste) }\end{array}$ & $\begin{array}{ll}\text { - } & \text { Aromatic aliphatic UDMA +Aliphatic dimethacrylates }(17 \% \text { wt }) \\
\text { - } & \text { Highly dispersed silicon dioxide }(19.7 \% \mathrm{wt}) \\
\text { - } & \text { Prepolymer/Copolymer }(62.8 \% \mathrm{wt}) \\
\text { - } & \text { Pigments }(0.1 \%)\end{array}$ & $\begin{array}{l}\text { Ivoclar Vivadent, } \\
\text { Liechtenstein } \\
\text { (R32664) } \\
\text { Shade: A3.5 }\end{array}$ \\
\hline $\begin{array}{l}\text { Direct nano-filled resin } \\
\text { composite } \\
\left(\text { Filtek }^{\mathbf{T M}} \mathbf{Z 3 5 0} \mathbf{X T}\right)\end{array}$ & 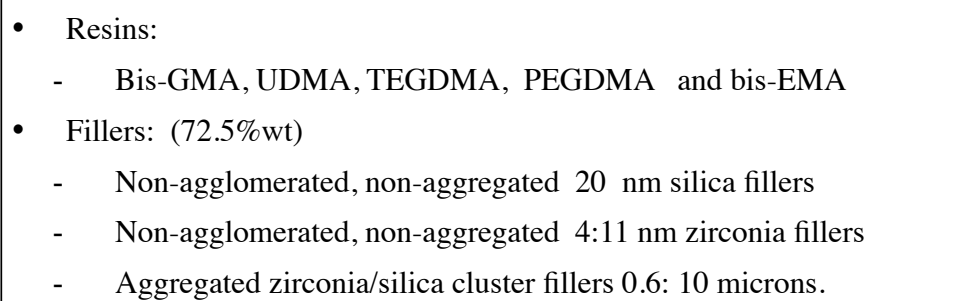 & $\begin{array}{l}\text { 3M ESPE, USA } \\
\text { (N436589) } \\
\text { Shade: A3.5 }\end{array}$ \\
\hline
\end{tabular}

flexural strength and disks (8x2mm) for measuring the surface microhardness. The first subgroup samples acted as the control subgroup, four subgroups were immersed into four different food simulating liquids (water, ethanol, heptane and citric acid) and last subgroup samples were thermocycled.

\section{Sample Preparation}

For Lava Ultimate $\left(\mathrm{M}_{1}\right)$; the bar samples were cut from the CAD/CAM blocks (Lava Ultimate, 3M ESPE, USA), using a low speed diamond disk (BesQual, NY 11373, USA) under profuse cooling. For disk samples preparation, the material block were converted into a cylinder with $8 \mathrm{~mm}$ diameter using a lathe machine then cut into disks with $2 \mathrm{~mm}$ thickness. All samples were polished using fine and extra-fine Sof-Lex ${ }^{\mathrm{TM}}$ disks (3M ESPE, USA)

For Nexco Paste $\left(\mathrm{M}_{2}\right)$ and Filtek Z350 XT $\left(\mathrm{M}_{3}\right)$, the samples were fabricated using split teflon molds. The composite resin material was packed inside the mold, pressed between two Mylar strips and two glass-slaps from both sides. Each sample was pre-cured using LED light curing unit (Radii Plus, SDI Limited, Australia) for 20 seconds in three consecutive points, producing a partial overlapping. The excess material was carefully removed with a scalpel blade. The $M_{2}$ samples were post-cured using manufacturer supplied light curing furnace (Lumamat ${ }^{\circledR} 100$ ) for 25 minutes.

\section{Immersion in food simulating liquids}

All samples were immersed separately into a tightly closed glass test tube for 1 month at room temperature. Food simulating liquids were; distilled water, $75 \%$ aqueous solution of ethanol, heptane and $0.02 \mathrm{~N}$ citric acid.

\section{Thermocycling}

The samples were thermo-cycled for $5000 \mathrm{cy}$ cles, each cycle includes immersion for 30 seconds into the hot path at $55 \pm 1^{\circ} \mathrm{C}$ followed by immersion for same time into the cold path at $5 \pm 1{ }^{\circ} \mathrm{C}$ with 5 seconds delay between the hot and cold paths. 


\section{Mini flexural strength measuring:}

The bar specimens were supported at each end using a jig with $10 \mathrm{~mm}$ distance between the two supporting points. Load is applied in the middle of the specimen using Instron ${ }^{\circledR}$ universal testing machine at a cross-head speed of $0.5 \mathrm{~mm} / \mathrm{min}$ until fracture. The flexural strength value was measured with the following equation ${ }^{(13)}$ :

Flexural strength $=3 \mathrm{PL} / 2 \mathrm{bd}^{2}$

Where: $\mathrm{P}=$ load at fracture,

$$
\begin{aligned}
& \mathrm{L}=\text { span length, } \\
& \mathrm{b}=\text { width and } \\
& \mathrm{d}=\text { thickness }
\end{aligned}
$$

\section{Surface micro-hardness measuring:}

Samples were tested under $100 \mathrm{gm}$ load with time of exposure $=10$ seconds using Vicker's micro-hardness tester (Wilson ${ }^{\circledR}$ micro-hardness tester, Tukon $^{\text {TM }}$ 1102, Buehler, USA). Three micro-hardness readings were recorded from each sample and the average value obtained from the micro-hardness tester softwear was recorded as the hardness value for the tested sample.

\section{Statistical Analysis}

Data were presented as means and standard deviation (SD) values. Data explored for normality using Kolmogorov-Smirnov and Shapiro-Wilk tests test for Normal distribution, data showed normal distribution so; One Way ANOVA was used to study the effect of different composites materials within each storage solution and thermocycling and effect of different immersion solution and thermocycling within each composite restorative. Duncan's posthoc test was used for pair-wise comparison between the means when ANOVA test is significant.

Kruskal Wallis test used to compare between different tested restoratives and immersion solution and thermocycling followed by Mann Whitney U-test for pairwise comparison

\section{RESUTLS}

\section{Mini Flexural Strength}

The mean and standard deviation of the mini flexural strength were obtained for the three tested materials; Lava Ultimate, Nexco Paste and Filtek Z350 XT before and after immersion into food simulating liquids and thermocycling and presented in (Table 2) and (Figure 1).

\begin{tabular}{|c|c|c|c|c|c|c|}
\hline & \multicolumn{6}{|c|}{ Restorative Materials } \\
\hline & \multicolumn{2}{|c|}{ Lava Ultimate $\left(\mathrm{M}_{1}\right)$} & \multicolumn{2}{|c|}{ Nexco Paste $\left(\mathrm{M}_{2}\right)$} & \multicolumn{2}{|c|}{ Filtek Z350 XT $\left(\mathrm{M}_{3}\right)$} \\
\hline & Mean [MPa] & SD & Mean $[\mathrm{MPa}]$ & SD & Mean $[\mathrm{MPa}]$ & SD \\
\hline $\mathrm{S}_{0 \text { (control) }}$ & 153.72 a A & 4.39 & $144.42 \mathrm{a} \mathrm{B}$ & 3.69 & $151.52 \mathrm{a} A$ & 2.44 \\
\hline$S_{1 \text { (water) }}$ & $133.33 \mathrm{~b} \mathrm{~A}$ & 3.17 & $127.66 \mathrm{~b} \mathrm{~B}$ & 3.00 & $126.06 \mathrm{~b} \mathrm{~B}$ & 2.09 \\
\hline $\mathrm{S}_{2 \text { (ethanol) }}$ & $124.67 \mathrm{~d} \mathrm{~A}$ & 3.40 & $114.82 \mathrm{~d} \mathrm{~B}$ & 3.43 & 104.66 e C & 2.80 \\
\hline $\mathrm{S}_{3 \text { (heptane) }}$ & $132.91 \mathrm{~b} \mathrm{~A}$ & 5.38 & 120.68 c B & 2.79 & 120.16 c B & 3.26 \\
\hline $\mathrm{S}_{4 \text { (citric acid) }}$ & $130.89 \mathrm{bc} \mathrm{A}$ & 2.05 & 120.52 c B & 1.96 & $119.36 \mathrm{c} \mathrm{B}$ & 1.72 \\
\hline $\mathrm{S}_{5 \text { (thermocycling) }}$ & $127.23 \mathrm{~cd} \mathrm{~A}$ & 3.23 & $117.12 \mathrm{~cd} \mathrm{~B}$ & 1.96 & $113.14 \mathrm{~d} \mathrm{~B}$ & 4.98 \\
\hline
\end{tabular}

Table (2) Descriptive statistics and test of significance of the effect of food simulating liquids and thermocycling on mini-flexural strength of the tested materials.

Results with the same letter are not significantly different within the same subgroup, 2 ways ANOVA ( $p \leq 0.05)$

Small Letters indicate the difference within the same column

Capital letters indicate the difference within the same row 


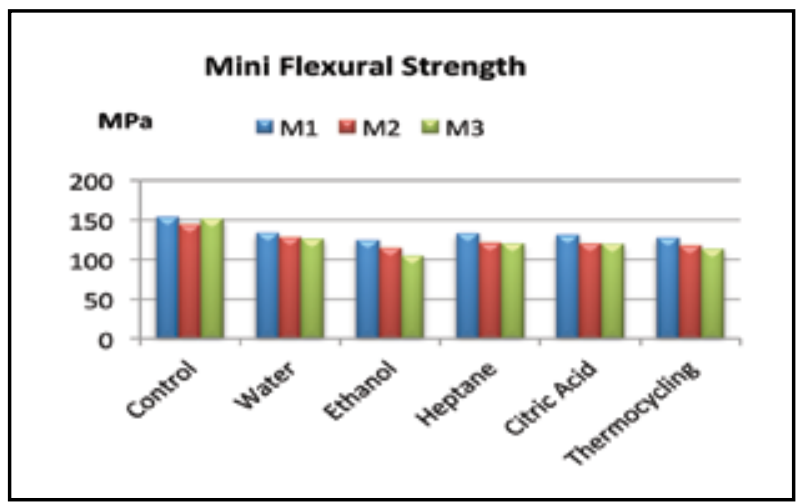

Fig. (1) A bar chart representing mini flexural strength of all investigated subgroups.

The significantly highest mean mini flexural strength values were observed before immersion in food simulating liquids and thermocycling (control subgroups) for the three tested materials; Lava Ultimate, Filtek Z350 XT and Nexco Paste with mean value of (153.72 MPa $\pm 4.39,151.52 \mathrm{MPa} \pm 2.44$ and $144.42 \mathrm{MPa} \pm$ $3.69)$ respectively as compared to those after immersion.

On the other hand, the lowest mean mini flexural strength values were observed with the samples immersed into ethanol for the three tested materials; Filtek Z350 XT, Nexco Paste and Lava Ultimate with mean values of $(104.66 \mathrm{MPa} \pm 2.8,114.82$ $\mathrm{MPa} \pm 3.43$ and 124. $67 \mathrm{MPa} \pm 3.4)$ respectively. Moreover, the samples of Filtek Z350 XT immersed into ethanol showed the lowest mean mini flexural strength values among all groups and subgroups.

\section{Surface Micro-Hardness}

The mean and standard deviation of the surface micro-hardness were obtained for the three tested materials; Lava ${ }^{\mathrm{TM}}$ before and after immersion in the food simulating liquids and thermocycling are presented in (Table 3) and (Figure 2).

Table 3. Descriptive statistics and test of significance of the effect of food simulating liquids and thermocycling on surface micro-hardness of the tested materials.

\begin{tabular}{|c|c|c|c|c|c|c|}
\hline & \multicolumn{6}{|c|}{ Restorative Materials } \\
\hline & \multicolumn{2}{|c|}{ Lava Ultimate $\left(\mathrm{M}_{1}\right)$} & \multicolumn{2}{|c|}{ Nexco Paste $\left(\mathbf{M}_{2}\right)$} & \multicolumn{2}{|c|}{ Filtek $\mathrm{Z} 350 \mathrm{XT}\left(\mathrm{M}_{3}\right)$} \\
\hline & Mean[VHN] & SD & Mean[VHN] & SD & Mean[VHN] & SD \\
\hline $\mathrm{S}_{0 \text { (control) }}$ & 67.06 a A & 4.54 & 44.10 a B & 3.54 & 40.82 a B & 4.33 \\
\hline$S_{1 \text { (water) }}$ & $54.3 \mathrm{~b} \mathrm{~A}$ & 2.13 & 37.76 b B & 3.21 & $35.18 \mathrm{~b} \mathrm{~B}$ & 2.62 \\
\hline $\mathrm{S}_{2 \text { (ethanol) }}$ & $41.78 \mathrm{~d} A$ & 1.42 & 29.08 e B & 2.22 & $25.88 \mathrm{~d} \mathrm{~B}$ & 3.09 \\
\hline $\mathrm{S}_{3 \text { (heptane) }}$ & $51.18 \mathrm{bc} \mathrm{A}$ & 2.34 & $35.74 \mathrm{bc} \mathrm{B}$ & 2.55 & $30.28 \mathrm{c} \mathrm{C}$ & 1.86 \\
\hline $\mathrm{S}_{4 \text { (citric acid) }}$ & $50.88 \mathrm{bc} \mathrm{A}$ & 3.07 & $34.02 \mathrm{~cd} \mathrm{~B}$ & 2.06 & $29.48 \mathrm{~cd} \mathrm{C}$ & 3.03 \\
\hline $\mathrm{S}_{5 \text { (thermocycling) }}$ & $48.46 \mathrm{c} \mathrm{A}$ & 4.43 & 31.54 de B & 1.71 & $27.26 \mathrm{~cd} \mathrm{C}$ & 1.91 \\
\hline
\end{tabular}

Results with the same letter are not significantly different within the same subgroup, 2 ways ANOVA ( $p \leq 0.05)$

Small Letters indicate the difference within the same column

Capital letters indicate the difference within the same row 


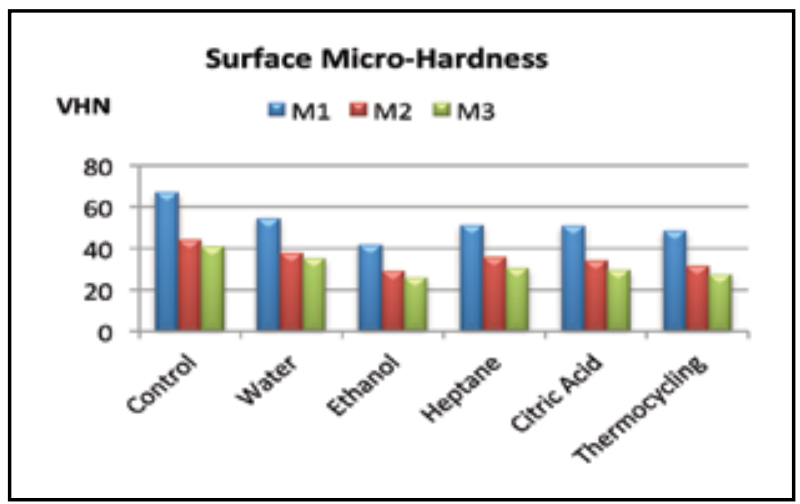

Fig. (2) A bar chart representing surface micro-hardness of all investigated subgroups.

The significantly highest mean surface microhardness values was observed before immersion into food simulating liquids and thermocycling (control samples) of Lava Ultimate (67.06 VHN \pm $4.54)$, followed by the samples of the same material immersed into water $(54.3 \mathrm{VHN} \pm 2.13)$, then the samples immersed into heptane (51.18 VHN \pm 2.34$)$ compared to the other subgroups. Moreover, there was no significant difference between the mean values of the Lava Ultimate samples immersed into water, heptane and citric acid.

On the other hand, the lowest mean surface micro-hardness values were observed with the samples of Filtek Z350 XT subjected to thermocycling $(27.26 \mathrm{VHN} \pm 1.91)$ and samples immersed into ethanol of the same material $(25.88 \mathrm{VHN} \pm 3.09)$. Moreover, there was no significant difference between them.

\section{DISCUSSION}

This study aimed to measure the mini flexural strength and surface micro-hardness of a resin nano ceramic material compared to an indirect microhybrid and direct nanofilled composite resin materials. The evaluation of the three restorative materials was done before then after immersion into food simulating liquids and thermocycling in an attempt to simulate the clinical conditions.
The FDA has proposed food simulating liquids in order to be used as an accelerating environment in sorption experiments, trying to indicate the impact of analogous foods on the polymer composites in long term ${ }^{(14)}$. Food simulating fluids can simulate the oral environment; distilled water simulates the wet oral environment provided by saliva and water, while heptane simulates butter, fatty meats and vegetable oils. The citric acid and ethanol simulate certain beverages including alcohol, fruits candies and syrups ${ }^{(10)}$.

Flexural strength test was performed using the three point bending test because of its lower standard deviation, and the less complex crack distribution when compared to those produced by other test designs, such as the biaxial flexural test ${ }^{(15)}$. The international standards Organization (ISO) recommend testing of the flexural strength for dental resin restorations with ISO 4094 specification ${ }^{(13)}$.

However, the large beam specimens $(25 \times 2 \times$ $2 \mathrm{~mm}$ ) as stipulated in this specification showed some limitations such as; difficult to prepare without flaws. Several overlapping irradiations are required as the exit window of all clinical light-cure units is smaller than $25 \mathrm{~mm}$. This leads to specimens that are not homogeneous as localized areas exposed to twice the curing time are inevitable ${ }^{(13)}$. In addition to material wastage, these large specimens are also not clinically realistic considering the fact that the mesio-distal diameter of molars is about $11 \mathrm{~mm}$ and the cervico-incisal lengths of central incisors is around $13 \mathrm{~mm}^{(13)}$. Moreover, the dimensions of the Lava Ultimate CAD/CAM blocks are too small to provide a bar with $25 \mathrm{~mm}$ in length because this material is suggested for manufacturing of inlays and veneers for single tooth only. Yap and Teoh (2003), advocated the use of mini flexural strength test for measuring the flexural properties of the composite restoratives. They stated that mini flexural strength test has the advantage of ease of specimen fabrication and is more clinically realistic ${ }^{(13)}$.Therefore, in the present study the flexural strength of the three types of evaluated composite resins has been examined 
using mini-flexural strength test. Vickers microhardness test was selected for this study because it is relatively a simple technique, very popular and reliable for obtaining the results ${ }^{(16)}$.

In general, the immersion into food simulating liquids and thermocycling showed a significant decrease in the mini flexural strength and surface micro-hardness of the three tested materials as reported by many authors ${ }^{(10,17,18)}$. Moreover, many authors ${ }^{(18-22)}$ noticed a decrease in the surface micro-hardness of composite resins after immersion of food simulating liquids. This is related to the susceptibility of polymeric matrix to sorption of different liquids. A portion of the liquid locates into the microvoids and the free volume among polymer chains without noticeable volume changes; a portion of the liquid however separates the polymer chains leading to an increase of the volume (swelling) ${ }^{(14)}$. Liquid uptake will moreover, leach unreacted components from the resin matrix, causing a reduction in mechanical properties ${ }^{(23)}$. Water can cause softening of the resin composites by its plasticizing effect ${ }^{(10)}$. In addition, $75 \%$ aqueous ethanol solution is the solvent that simulate and accelerate the aging of resin composite ${ }^{(24)}$. Citric acid could simulate the oral environment as they found in many beverages and foods. Thermal shock by hot drinks and foods also participate into the resin composite degradation ${ }^{(24)}$.

The reduction in mechanical properties of dental composite resins by water uptake may be due to three factors; the first factor is due to water that swells the polymer matrix and occupies space between the main chains and cross links, as well as filling microvoids created during polymerization. It is possible at the same time that the water may cause some hydrolysis of the filler / matrix interfaces, and /or crazing of the polymer matrix which would contribute to the reduction in properties. The second factor is that all the composites evaluated contained silica or silicate glass fillers that have irregularly distributed Si-O-Si bonds. When the composites are immersed in water, the resin matrix swells and radial tensile stresses are introduced at the filler interfaces, straining the Si-O-Si bonds in the fillers making the filler more susceptible to stress corrosion attack, resulting in complete or partial filler debonding. The Last factor is due to the hoop stresses that are also exist around the filler particles as a result of matrix shrinkage during polymerization. These hoop stresses increase the frictional forces between filler and resin matrix, thereby decreasing the filler pullout tendency during flexural testing. After aging in water, the plasticizing and swelling of the resin matrix reduces the hoop stresses around the fillers and facilitate their pull out ${ }^{(17)}$.

The $75 \%$ ethanol solution has a close solubility parameter to Bis-GMA-based materials, and the closer the solubility parameter between solvent and solute, the greater the solute's degradation ${ }^{(20)}$.

Heptane decreases the mechanical properties of the composite resin materials as it is an organic solution that can potentially damage the resin matrix, producing cracks in the interface, and consequently, weakens the material ${ }^{(19,21,25)}$. In addition, degradation of the inorganic fillers may also play a role in the reduction of the material properties ${ }^{(25)}$.

The immersion in citric acid affects both the fillers and the matrix. When the composite resin exposed to low $\mathrm{pH}$ environment, the inorganic fillers tend to fall out from resin material and the matrix components decompose. Consequently, leakage of filler constituents has been shown to produce cracks at the resin- filler interface, which may lead to weakening of the material ${ }^{(19)}$.

Thermocycling is a combination of hydrolytic and thermal degradation and a method to simulate temperature-related breakdown by repeated sudden temperature changes ${ }^{(26)}$. Prolonged thermocycling may lead to water absorption by a diffusion-controlled process, and it causes leaching of unreacted monomers and swelling of the matrix. Water acts like a plasticizer and thereby weakens the polymer structure. It also degrades the matrix/filler interface directly by hydrolytic breakdown of the silane/filler 
interface and the surface of the filler particles, hence decreasing the mini flexural strength and surface micro-hardness of the three tested materials. Some authors ${ }^{(26,27)}$ found a decrease in the flexural strength after thermocycling, others ${ }^{(28)}$ reported that thermocycling decreased the surface micro-hardness of the composite resin materials. On the other hand, others ${ }^{(26)}$ found an increase in the surface microhardness of indirect composite resin materials after thermocycling and claimed that findings to the $55^{\circ} \mathrm{C}$ of the thermocycling water path temperature which leads to further polymerization of the surface of the composite resins.

The results of the mini flexural strength and surface micro-hardness of the present study showed that the samples of Lava Ultimate before immersion into food simulating liquids and thermocycling recorded significantly higher values compared to Nexco Paste and Filtek Z350 XT. The higher flexural strength and surface micro-hardness of Lava Ultimate $\left(\mathrm{M}_{1}\right)$ may be related to its higher filler content ( $80 \%$ wt fillers) compared to the other two tested materials ${ }^{(15)}$ The higher filler loading with smaller particle size provides a reduction in the interstitial spacing, which effectively protects the softer matrix, reduces the incidence of filler exfoliation, and enhances the material's overall resistance to abrasion ${ }^{(29)}$. Moreover, resin composites with nanofiller showed higher flexural strength than resin composites with microhybrid fillers ${ }^{(30,31)}$. In addition, secondary polymerization of the indirect composites produces a greater degree of polymerization that improves the strength and hardness of composites ${ }^{(32)}$.

In the present study, the samples immersed into ethanol showed the lowest mean mini flexural strength and surface micro-hardness values in the three tested materials compared with the other immersion liquids and thermocycling. Organic solvents like ethanol have the potential for polymer damage. It can penetrate the resin matrix fully and promote the release of unreacted monomers. The partial dissolving of the resin matrix may result in the degradation of the filler-matrix interface, thereby impairing the flexural strength ${ }^{(9,10,27)}$ and the surface micro-hardness ${ }^{(18-20)}$.

\section{CONCLUSION}

1. The food simulating liquids and thermocycling affects mini flexural strength and surface microhardness of the all tested materials.

2. The ethanol as a storage medium has the most deteriorating effect on mini flexural strength and surface micro-hardness of all the tested materials.

3. Among all the materials tested, Lava Ultimate seems to be the most stable in different food simulating liquids and thermocycling regarding the properties tested.

\section{REFERENCES}

1. Lynch CD, Frazier KB, McConnell RJ, Blum IR, Wilson NHF. Minimally invasive management of dental caries. J Am Dent Assoc. 2011;142(6):612-20.

2. 2. Niewczas AM, Pieniak D, Ogrodnik P. Reliability Analysis of Strength of Dental Composites Subjected to Different Photopolymerization Procedures. Eksploat I Niezawodn Reliab. 2012;14(3):249-55

3. Chan K, Lee Y, Nicolella D. Improving fracture toughness of dental nanocomposites by interface engineering and micromechanics. Eng Fract Mech . 2007;74(12):1857-71.

4. Krithika A, Kandaswamy D, Sathish ES. Wear analysis of nano ceramic composites against a ceramic antagonist. J Conserv Dent. 2006;6(4):152-8.

5. Vilotić M, Lainović T, Kakaš D. Roughness analysis of dental resin-based nanocomposites. J Prod Eng. 2012; (June):2-5

6. Lainović T, Vilotić M, Blažić L, Kakaš D, Marković D, Ivanišević A. Determination of surface roughness and topography of dental resin-based nanocomposites using AFM analysis. Bosn J Basic Med Sci. 2013 Feb; 13(1):34-43.

7. Korkmaz Y, Ozel E, Attar N, Aksoy G. The influence of one-step polishing systems on the surface roughness and microhardness of nanocomposites. Oper Dent. 2008; 33(1):44-50. 
8. Coelho Santos G, Coelho Santos MJM, Rizkalla AS, Madani DA, El-Mowafy O. Overview of CEREC CAD/ CAM chairside system. General Dentistry. 2013.p. 36-40.

9. Vouvoudi EC, Sideridou ID. Effect of food/oral-simulating liquids on dynamic mechanical thermal properties of dental nanohybrid light-cured resin composites. Dent Mater . The Academy of Dental Materials; 2013 Aug; 29(8):842-50.

10. Yesilyurt C, Yoldas O, Altintas SH, Kusgoz A. Effects of food-simulating liquids on the mechanical properties of a silorane- based dental composite. 2009;28(3):362-7.

11. 3M ESPE. Lava Ultimate. Technical Product Profile.

12. Awada A, Nathanson D, Coldea A, Swain M V., Thiel N, Della Bona A, et al. Mechanical properties of resinceramic CAD/CAM restorative materials. Dent Mater . Editorial Council for the Journal of Prosthetic Dentistry; 2015;114(4):564-9.

13. Yap A, Teoh S. Comparison of flexural properties of composite restoratives using the ISO and mini-flexural tests. J Oral Rehabil . 2003 [cited 2015 Oct 20];30:171-7.

14. Sideridou ID, Vouvoudi EC, Keridou I V. Sorption characteristics of oral/food simulating liquids by the dental light-cured nanohybrid composite Kalore GC. Dent Mater. 2015;31(9):e179-89.

15. Hamouda I, Elkader H. Evaluation the Mechanical Properties of Nanofilled Composite Resin Restorative Material. J Biomater Nanobiotechnol . 2012 ;2012(April):238-42.

16. Marghalani HY. Post-irradiation vickers microhardness development of novel resin composites. Mater Res. 2010;13(1):81-7.

17. Satish G, Nainan MT. Invitro evaluation of flexural strength and flexural modulus of elasticity of different composite restoratives. J Conserv Dent. 2006;9(4):140-7.

18. Muley BY, Shaikh SR, Tagore MM, Khalikar AN. Effect of Dietary Simulating Solvents on the Mechanical Properties of Provisional Restorative Materials-An In Vitro Study. J Indian Prosthodont Soc . Springer India; 2014;14:98-105.

19. Al-wahab ZN. An evaluation of the effect of different solutions on the microhardness of aesthetic restoration. MDJ. 2011;8(2):106-14.

20. Münchow EA, Ferreira ACA, Machado RMM, Ramos S, Rodrigues-junior SA, Zanchi CH. Effect of Acidic Solutions on the Surface Degradation of a Micro-Hybrid Composite Resin. Braz Dent J. 2014;25(4):321-6.
21. Torres CR, Silva TM Da, Sales ALLS, Pucci CR, Borges AB. Influence of Chemical Degradation and Toothbrushing on Surface of Composites. World J Dent. 2015;6(June):65-70.

22. Peampring C, Sanohkan S. Effect of Thermocycling on Flexural Strength and Weibull Statistics of Machinable Glass-Ceramic and Composite Resin. J Indian Prosthodont Soc . 2013;14(4):1-5.

23. Kooi T, Tan Q, Yap A, Guo W, Tay K, Soh M. Effects of Food-simulating Liquids on Surface Properties of Giomer Restoratives. Oper Dent . 2012;37(6):665-71.

24. Tabatabaei MH, Sadrai S, Bassir SH, Veisy N. Effect of Food Stimulated Liquids and Thermocycling on the Monomer Elution from a Nanofilled Composite. 2013;62-7.

25. Akova T, Ozkomur A, Uysal H. Effect of food-simulating liquids on the mechanical properties of provisional restorative materials. Dent Mater. 2006;22:1130-4.

26. Souza RO a, Özcan M, Michida SM a, de Melo RM, Pavanelli $\mathrm{C}$ a., Bottino $\mathrm{M}$ a., et al. Conversion degree of indirect resin composites and effect of thermocycling on their physical properties. J Prosthodont. 2010;19(3):218-25.

27. Stawarczyk B, Egli R, Roos M, Özcan M, Hämmerle $\mathrm{CHF}$. The impact of in vitro aging on the mechanical and optical properties of indirect veneering composite resins. J Prosthet Dent . The Editorial Council of the Journal of Prosthetic Dentistry; 2011;106(6):386-98.

28. Oliveira JC De,Aiello G, Mendes B, Urban VM, Campanha $\mathrm{NH}$, Jorge JH. Effect of storage in water and thermocycling on hardness and roughness of resin materials for temporary restorations. Mater Res. 2010;13(3):355-9.

29. Paula AB De, Caroline R, Alonso B, Albamonte G, Araújo $\mathrm{S}$ De, Rontani JP, et al. Influence of chemical degradation and abrasion on surface properties of nanorestorative materials. Braz Dent Sci. 2015;14(2):100-5.

30. Garapati SN, Priyadarshini, Raturi P, Shetty D, Srikanth $\mathrm{KV}$. An in vitro evaluation of diametral tensile strength and flexural strength of nanocomposite vs hybrid and minifill composites cured with different light sources (QTH vs LED). J Contemp Dent Pract . 2013;14(1):84-9.

31. Pontes L, Alves E, Alves B. Mechanical properties of nanofilled and microhybrid composites cured by different light polymerization modes. Gen Dent . 2013 [cited 2014 Nov 25];61(June):30-3.

32. Mazumdar P, Das UK, Majumdar N. Degree of conversion of indirect composite resin under Fourier transformation infrared spectroscopy - An in vitro study. Int J Adv Case Reports. 2015;2(23):1410-7. 